\title{
Algunos documentos medievales riojanos
}

\author{
Pedro Andrés Porras Arboledas \\ Universidad Complutense de Madrid
}

\begin{abstract}
RESUMEN
ABSTRACT

Se recoge en este artículo un elenco de ocho documentos de la época medieval procedentes del Archivo Provincial de La Rioja, uno del Conde Fernán González, otro de Alfonso el Emperador, dos de Alfonso el Sabio, otro de Sancho IV y dos más de Alfonso XI. Algunos de ellos están publicados, pero o bien interesa su reedición por tratarse de versiones nuevas o bien por haberse hecho una relectura de textos difíciles de entender. Salvo el primero y el último, los demás son documentos reales. Cinco de ellos procedian del Archivo municipal de Mansilla, dos del de Sajazarra y otro más del de Entrena.

Tienen en común el ocuparse de temas de términos, privilegios y ordenanzas. De hecho, el último documento es el más interesante, al tratarse de un texto municipal en el que se recogen detalladas normas penales y de policía rural aprobadas en fases sucesivas, en la segunda mitad del siglo Xiv, por el concejo de Sajazarra.

This article contains a group of eight documents of the middle ages from the Province Archive of La Rioja; belonging one to the Count Fernán González, another one belongs to Alfonso the Emperor, two more to Alfonso the Sage, one to Sancho IV and two more to Alfonso XI. Although some of them have been already published, it is interesting either the reissuing, as they are new releases or a new reading of these texts, that are so difficult to understand. Except the first and the last one, the rest of the texts are Royal Documents. Five of them came from the Municipal Archive of Mansilla, two from that of Sajazarra and another one from that of Entrena. All of them have in common the dealing with subjects such as terms, privileges and ordinances. In fact, the last document is the most interesting one, as it is a municipal text, and in which there are detailed contained penal and police laws, approved in successive phases, in the second half of the XIV century, by the Council of Sajazarra.
\end{abstract}


En una reciente visita al Archivo Histórico Provincial de La Rioja tuve la oportunidad de consultar la documentación medieval que en él mismo se conserva; lo cierto es que no es muy alto el número de documentos existentes, aunque algunos de ellos revisten un particular interés. De hecho, he recogido tan sólo ocho textos: uno del Conde Fernán González, otro de Alfonso VII, dos de Alfonso X, uno de Sancho IV, dos de Alfonso XI y otro emanado de un concejo ${ }^{1}$. Como en muchos otros archivos provinciales, en el de La Rioja se ha seguido en los últimos años una política de recuperación de archivos municipales, los cuales se inventarían y quedan depositados en aquellos otros; como resultado de esa política se han recolectado distintos archivos que contienen algunos privilegios medievales.

Esto sucede, especialmente, en los archivos de Mansilla y Sajazarra; de aquél he recogido cinco documentos, tres de ellos procedentes de un proceso de 1739 , con lo que la transcripción de algunos puede presentar, incluso, un aspecto ciertamente sospechoso - véase para ello el documento 5, pertinente a Sancho IV, transcrito en su día muy deficientemente-; sin embargo, el hecho de que se trate de privilegios cuyos originales no se conservan, les confiere un particular interés. Todos son inéditos ${ }^{2}$, salvo el documento del primer conde independiente castellano, que es bien conocido, aunque no en esta versión. Otros dos documentos de Mansilla son privilegios originales en pergamino de Alfonso $X$ y Alfonso $X I$.

El segundo aporte de documentos procede del archivo municipal de Sajazarra; se trata de dos documentos ya publicados en su día por José G. Moya; si vuelvo a editarlos es por su interés y porque la dificultad de su lectura -en especial del documento 8- bien merecian una segunda criba que mejorase, en la medida de lo posible, la anterior.

Respecto al documento 2 no podemos decir que proceda del archivo municipal de Entrena; por una curiosa circunstancia, el privilegio en cuestión fue donado al archivo provincial, sin que exista ningún otro documento de esa procedencia en ese archivo.

¿Qué aportación se hace, pues, en este trabajo? Publicamos por vez primera cuatro documentos, hasta ahora inéditos, que sepamos (documentos 4 ,

1. Recientemente, he tenido ocasion de publicar otro documento medieval procedente de este mismo archivo; se trata de una carta de Hermandad (1412, noviembre 3. El Hospital) entre los concejos de Anguiano, Matute y Tobía y, por otra parte, el de Brieva, para la salvaguardia de sus términos y ganados ("La juridiction pénale des Hermandades castillanes au Moyen Âge", Cahiers de I'Institut d'Anthropologie Juridique [Université de Limoges], IV, 2000, pp. 62-64).

2 El documento 1 ha sido editado también, entre otros, por Fidel Fita en un conjunto de artículos sobre las Cinco Villas, publicados en el n. ${ }^{\circ} 50$ del Boletín de la Real Academia de la Historia, correspondiente a 1907, pp. 271-310, 316-321, 359-404 y 471-485; también cita la existencia de los documentos 4,5 y 7 (ver la referencia en cada caso). 
5,6 y 7); volvemos a presentar los dos documentos de Sajazarra (documentos 3 y 8), tras una difícil relectura con rayos ultravioleta, y, finalmente, damos a conocer una versión, que hasta ahora se creía perdida ${ }^{3}$, del presuntamente falso privilegio de Fernán González (documento 1), así como una transcripción, mucho más cercana al original que el texto que hasta ahora se conocía, del Fuero de Entrena con su confirmación (documento 2); en ambos casos se encuentran variantes que pueden aclarar la comprensión de su contenido.

Respecto al documento 1 , se trata de un curioso privilegio traducido al castellano, atribuido al primer conde, conteniendo tanto los términos concedidos a Canales y Cinco Villas como algunos fueros, relativos al fonsado, yantares y otras normas de derecho procesal, penal y tributario. Con posterioridad, aunque en estos dos casos el privilegio no va fechado, se añaden sendos privilegios del conde Sancho García y del rey Fernando I, relativos respectivamente a la protección de los términos señalados y a la concesión de exenciones de diverso tipo, así como un acuerdo sobre los derechos de los ganados de los vecinos de la zona. Se trata de una versión hasta ahora inédita de este privilegio, que Zabalza considera falso, y que en unos casos es más clara que la versión conocida y en otros puntos resulta más confusa ${ }^{4}$.

Por su parte, el documento 2 es una confirmación inserta en un privilegio de Juan II; el texto va sin fecha, pero no así el texto también latino de Fernando III confirmándolo. Considero esta versión más completa que la que en su día publicó Tomás González y con variantes de interés. Se trata de la concesión a la villa de Entrena de varios privilegios, el principal de ellos el uso del Fuero de Logroño.

El tercer documento es la concesión de términos en 1255 por Alfonso $X$ a los de Sajazarra. Al tratarse de un privilegio rodado, incluye una larga lista de confirmantes.

El cuarto procede del mismo rey y año y reviste un mayor interés desde el punto de vista jurídico, por cuanto viene a regular el régimen del homicidio, de acuerdo con su propio fuero, según que fuese cometido por vecino, hijo de vecino y fuere manifiesto o no; también se ocupa del homicidio demandado al

3 A comienzos del siglo xIx el proceso de 1739, donde estaban copiados los documentos de Mansilla, se situaba en el Archivo Municipal de Villavelayo, en donde no se encontraba años después. No sé a ciencia cierta si el que he visto procedente del de Mansilla es exactamente el mismo libro conteniendo el proceso o se trata de una copia del mismo (ZABALZA DUQUE, Manuel: Colección Diplomática de los Condes de Castilla. Edición y comentario de los documentos de los condes Fernán González, García Fernández, Sancho García y García Sánchez, Valladolid, 1998, doc. 9, pp. 179-186).

4 El propio Zabalza termina su comentario a este documento con las siguientes palabras: «Y nos sumamos a las calificaciones de falsedad con la esperanza de que algún día aparezcan, tanto la versión latina como la copia romance del archivo de la Chancillería para revisar con más rigor nuestros juicios de hoy" (p. 186). 
concejo. Regula el juramento compurgatorio y la pena de los cojuradores que mintieren. A cambio de esta merced, el monarca les impone que funden una capellania que perpetuamente rezase por su padre, él mismo y sus sucesores.

El problemático privilegio de Sancho IV, por su parte, recoge de una forma un tanto confusa una serie de exenciones concedidas a los vecinos de Cinco Villas y Canales: básicamente, este rey les exime de pechos, yantares, homicidios, fonsados, fonsaderas y cualesquier otros tributos que pagasen con ocasión de las fiestas de San Miguel y San Martín; además, incluye un mandato al merino mayor de Castilla prohibiéndole entrar dentro de los términos de estos concejos.

El documento sexto, debido a Alfonso XI, es una confirmación de los términos antiguos del concejo de Canales y sus villas, que viene a reproducir los mismos hitos que el documento de Fernán González, recogido en primer lugar.

También el mismo monarca concedió a los mismos destinatarios otro privilegio, esta vez, a petición de aquéllos, concediéndoles que permanecieran siempre dentro de la Corona real, pues previamente le habian recibido como su señor.

Sin embargo, el texto más interesante de todos, a mi juicio, es el último; en el mismo, el concejo de la villa de Sajazarra en cinco momentos distintos, entre 1366 y 1399, aprueba un conjunto de 38 disposiciones, que materialmente versan sobre dos temas: derecho penal y policía rural. Dentro de la normativa criminal, destacan de forma apabullante los preceptos que se refieren a las injurias inferidas de distintas formas, con una interesante noticia sobre la entrada de las tropas inglesas en la villa durante la guerra civil de mediados de siglo (\# 30); otros supuestos penales recogidos serían las lesiones o la posesión de armas.

En el ámbito de la policía rural se incluyen diversas conductas relativas al incumplimiento de obligaciones comunales, daños causados por personas $y$ animales en fincas ajenas, etc.

Esie documento resulta igualmente interesante desde el punto de vista de la tipología del texto; en efecto, dado el modo de promulgarse estos preceptos y el órgano del que surgieron, podrian clasificarse como ordenanzas; sin embargo, teniendo en cuenta parte de las materias que se insertan, bien podrían considerarse como un fuero, por cuanto la materia penal, salvo excepciones, no era una cuestión que en estas épocas siguiera quedando acometida a los municipios. Es por ello por lo que creo que se trata de una mixtura de ambos documentos, en un momento en el que la documentación es precisamente poco numerosa; se trataría, por tanto de un momento de transición en el que los concejos siguen conservando alguna capacidad normativa en el campo penal, formulándose como ordenanzas municipales. 


\section{DOCUMENTO 1}

\section{4, enero 17}

El Conde Fernán González concede términos y fueros a las Cinco Villas y a Canales.

AHPLa Rioja, A.M. Mansilla, 109/14, fol. 131v-136v. Traslado en proceso seguido por las Cinco Villas y la villa de Canales con el Conde de Aguilar sobre los derechos señoriales de éste (1739).

Ed. Fidel Fita, op. cit., pp. 317-319.

Ed. Manuel Zabalza Duque, Colección diplomática de los Condes de Castilla, Valladolid, 1998, doc. 9, pp. 179-182.

En el nombre del Padre y del Hixo y del Espíritu Santo, que es un solo Dios y una criatura Deidad, yo Fernán González, por la gracia de Dios, Conde de toda Castilla enperante, la qual grazia otorgante de mi voluntad doy e otorgo los términos y fueros a la villa de Canales que las aia firme para siempre jamás fasta la fin del siglo, dende la Golla fasta la Filiportica, Oter del Cuerbo y a Sierra Corta fasta la Golla de Arada, e por el Lombo Mediano a Sinestras Redondo y a el Río Aranda aiuso fasta la Vega del Toro e a Campo Luengo a suso de Astexón de Vere a Azeda y por el sendero a Campo de Yuso de el Lombo Zerezo.

Por aquesto juraron dos en oxidos de Ventrosa, que de Canales y de sus Villas devia ser, he aze puerto fasta los dos foios de Monte Rubio y a San Christóbal y a era Contestero y a la Peña de el Güitre y el Pandal del Caldo y a Santa Coluna por la Lastra a suso, a somo de Gramone, y a la caveza en Alior de Gramone y a Matafuero y al Río de Neila y al Campo de Olegane y a somo de Ferrara y al Collado de Parafita y a la Puerta de Arbión y acá y quede Raia Tormosalbos y al Colado Grande y al Collado Guitra y a la Caveza de Tabladas y al Collado Cavallar y a Peñarrubia y por el Somillo de Cobiellas dezienden al Campo y fieren al Río de Neila y Río a suso a Cobiella e a aquel Lombo Çaragozano a suso a la Caveza de la Endrinera y dende somo fasta la Caveza del Foio Vellido y al Collado de Finestrar caia la Caveza de Repaxal, e dende a Cogollas.

$Y$ ser todo aquesto doy fuero a la villa de Canales, que baian en el fonsado la quarta parte y en finque las tres, y si no quisieren hir al fonsado pechen sendos carneros, quien no ubiere carnero peche el sueldo; a el señor que hubieren de'nden vi yantar en todo el año, un día pan y vino y carne y zevada, y al merino sírvalo días el juez con todos los ombres y dos cavallos y de lo que estuviere el juez de suso e a ellos y el balle[s]tero aia doze almudes a el zenar y ocho a él y yantar, y el escudero aia ocho almudes a el zenar y seis al aiantar, y al terzero día baian su carrera, y de tres semanas 
aiuso bengan y si más les quisieren aian morar de suio se esopedan a los ombres desafiados que no fallaren una vez, benga otra vez y fagan los afiar aquellos que le mandare, y si no quisieren afiar, mórense aquel en su casa y el que saión fuere que en testimonio lo firme, y si no hubiere testimonio caian la jura de el mezquino. $Y$ de plaga que huesos salieren cien sueldos aia, y de el diente delantero cien sueldos y otro diente veinte sueldos, y llaga falta el hueso diez sueldos, y plaga de la una parte a la otra veinte sueldos, y sangre a tierra cinco sueldos, y por otra parte quanto la apreziaren los sus ombres ombres y los suios. $Y$ si alguno hubiere feridas en su cuerpo y no tome de aquel que las fizo y el palazio non aia ninguna cosa; y si el dueño de aquellas feridas tomare alguna cosa quanto aquel pusiere, el palazio tome lo medio; y si acoechare con el señor de las feridas, el palazio tome lo medio. $Y$ de maior tiguazión que en tierra echare, peche sesenta sueldos a el palazio los medios y a pan en tierra. $Y$ si boz a palazio no echare, el palazio no aia ninguna cosa. $Y$ si boz a palazio echare sáquelo a somo. El que fixa axena forzare sesenta sueldos peche al palazio los medios y agan en tierra y sus aras delanteras a ella. E si bos a palazio no echare el palazio no aya ninguna cosa. E si bos a palazio echare, si se salbare aquel que lo fizo non abrá aquella muxer ninguna calona. $Y$ si la muxer no echare bozes, non aia el palazio ninguna cosa.

$Y$ si alguno de nuestros fixos, nietos, propinquos o de estraños de los prinzipes o de los potestades o de algunos ombres aquesta nuestra confirmazión o donazión mudar o romper quisieren sean de Dios señor malditos y confundidos y de la compañía de los christianos sean apartados y a la fin conxurados, el traidor aian traizión en el ynfierno más baxo, y ser todo aquesto a la parte de el Conde paguen cinco marcos de plata.

E yo Fernán González Conde, de aquesta donazión quize fazer, señal de cruz ficet. Testigos por robeallo pus a Pedro, obispo de Baquizes. Gonzalo Fernández. Sancho Fernández. Gonzalo Avir. Bol Boca e aquel. Obeco Osores. Diego Fernández. Albaro Sura. Nuño Lainez. González Télez. Gutiérrez Gómiez. Obero Núñez. Noño de Gostioz. Guedole de Canales. Liba Hermoti. Todo el zimiterio dio a Santa María de Canales. Fecha esta carta en la hera de novezientos y setenta y dos años.

Yo, pues que ansí es, Sancho, Conde en todo Castilla enperante, acaeziome en un tiempo que llegué a correr caza con ombres de villa de Canales y de Valdelaguna en Monteferrero, y quando me torné plogome de establezer quier en aquel monte arase y ronpiese quantos árboles taxase, tantas libras de oro pagase a la parte del Conde, y entonzes luego testimonio afianzar lo de escrivano. Ruy Guditros el mexorado. Nuño Albarez. Sancho Téllez. Mostago de Canales. Gómez de Oneca. Garzía Garzés. Nuño Benego de Zuerta. Letra en la carta, en la hera sobredicha. 
Yo, pues que así es, Fernando Rey, con mi muxer Sancha Reyna, damos fuero a la villa de Canales que en toda nuestra tierra non aian ni paguen portazgo e de toda corona en que caieren del palazio, ansí como de mansiellas y amortiguazión y de omizido sin voluntad peche un buey, e de mansillas contenidas danenxeles, e plaga. E yo Fernando Rey, de mi espótica voluntad, fago combenientia con Baldecanalaes y Zinco Villas de aquellas montañas de Duero en acá tomen de los ganados merinos de la grey de las obexas, carnero y cordero, del busto de las bacas, carnero y en olivares y en quantos en la de Baldeavellanos y en Zerrato y en Balcavamión en toda nuestra tierra do ierba allaren y refieran los ganados de las mieses y pazcan la yerban de Diero y ante tomen Peñafiel y ansí como de suso diximos, lo medio para sí y lo medio para el Rey, carnero y cordero y de el busto de las bacas, ca[r]nero. Yo Fernando Rey asi lo confirmo aquel testamento que fizo mi abuelo Sancho Conde de aquel Monteterrera, que quien en aquel monte arare y ronpiere que quanto árboles traxere, tantas amas de oro pague a la parte del Rey.

$Y$ si alguno de nuestros fixos, nietos, propinquos o estraños de los prínzipes y de las potestades, alguno de los ombres aquesta nuestra confirmazión o donazión mudare o ronper quisiere, sean de Dios, nuestro Señor, malditos e confundidos de la compañía de los christianos y sean apartados a la fin con Judas el traidor aia razión en el Infierno más abaxo. Amén. Y sobre todo aquesto a la parte del Rey paguen zinco marcos de plata.

Qu'es que ansí es yo Fernando Rey que aquesta donazión quise fazer, señal fize de cruz, escrivano a firmarlo de su razón.

Núñez. Don Nuño Albarez. Fernando Ruiz. Don Tedelio de Canales. Gómez de Laio de Mansilla. 


\section{DOCUMENTO 2}

1218 [agosto 14]. Carrión

Fernando III confirma a Entrena el Fuero de Logroño concedido por Alfonso VII.

AHPLa Rioja, Entrena, doc. 1. Privilegio original de 1408; pergamino.

Ed. Tomás González, Colección de privilegios, exenciones y fueros, concedidos a varios pueblos y corporaciones de la Corona de Castilla, copiados de orden de S.M. de los registros del Real Archivo de Simancas, Madrid, 1829-1883, vol. V, pp. 136-137, doc. XXXV.

Ed. Gonzalo Martínez Díez, "Fueros de La Rioja», Anuario de Historia del Derecho Español, XLIX, 1979, doc. 13, pp. 419-420, y Julio González, Reinado y diplomas de Fernando III. II. Diplomas (1217-1232), Córdoba, 1983, p. 47, doc 38.

Ordo nostro et posteris presentibus innotescat quod ego Ferrandus, Dey gratia, Rex Castelle et Toleti, inveni quandam cartam a serenisimo proano meo Inperatore donon Alfonso factan et concesam infançonibus et villanis que in Antelena popularunt et ibi moranti erant, suisque posteris omnibus in hunc modum:

«In nomine Domini, ego Alfonsus Yspanie Inperator, cum uxore mea domina Verengaria, spontanea voluntate, facio cartam donaçionis et confirmaçionis vobis infançonibus presentibus et futuris qui populantis in Antelena et moranti estys uc habeatis talen forum qualen [ha]buerunt vestros avolos.

Dono eçiam bobis et conçedo que domos vestros et omnes ereditates vestras quas ibi habetys et habetys vel conpanendas vel aquisientys, cun ingresibus e exinibus omne tempore posideatis illas et habeatis liberas sine ulla contradiçione sicut vestri avi habuerunt.

Dono itaque vobis illa serna de Soto Castillero ubi facitis ortos.

Conçedo eçiam vobis omnes pratus qui sunt in termino vestro sine ullo malo foro ut habeatis illos omni tempore in paçen.

Dono itaque omnibus villanis qui pop[u]lat[i] sunt vel populaverunt in Antelena ut habeant foro de Logroño.

Conçedo eçiam vobis omnibus tam infançonibus quam villanis quod non habeatis forun exire in apellido a quo vadatis unum die et in aliu veniatis at domos vestras".

Supradi[ct]am itaque donaçione atque confirmaçione, ex asensu et bene et placito done Verengarie, regine ginitrias me, una cun fratre meo, infante dono Alfonso, conçedo vobis conçilio de Antelena sopredicto, presenti et futuru perpetuan valituran. 
Si quis aute hoc mee donaçionis atque confirmaçionis previllegium infringere seu deminuere atentaverit vel et in aliquo presunpserit contraire, iram Dei omnipotentus plenarie incurrat et cum luda Domini traditore penas susteneat infernales, et regie parte mille auredes in pena petuet et danun vobis super oc illatun restituat duplicatun.

Facta carta apud Carrionen, .xix. Irlas [sic] septenbris, era millesima duçentesima quinquagesima sesta, anno reni mei secundo.

E ego Rex Ferrandus, regnans in Castella et Toleto, hanc cartam quam fieri iusi manu propria roboro et confirmo. Petri iusit cancellarii scripsit.

Confirmado en el Real de Lerma, 22-IX-1336.

Idem en Cortes de Toro, 15-IX-1371.

Idem en Cortes de Burgos, 20-VIII-1379 (privilegio rodado).

Idem en Burgos, 20-II-1392 (privilegio rodado).

Idem en Alcalá de Henares, 27-II-1408 (documento original). 


\section{DOCUMENTO 3}

1255, mayo 29. Palencia

Alfonso $X$ concede a los de Sajazarra que tengan libremente sus términos.

AHPLa Rioja, A.M. Sajazarra, 24. Pergamino, inserto en carta de personería de 6 de noviembre de 1327.

Ed. José Gabriel Moya Valgañón, «Notas sobre Sajazarra medieval: urbanismo, cerca, fortaleza", Cuadernos de Investigación Histórica. Brocar, XVI, 1990, doc. 1, p. 122.

Conosçuda cosa sea a todos los omnes que esta carta vieren cuémo yo don Alfonso, por la gracia de Dios, Rey de Castilla, de Toledo, de León, de Galisia, de Sevilla, de Córdoba, de Murçia, de Jahén.

En uno con la Reyna doña Violante, mi muger, et con mis fijas la Infante doña Berenguela e la Infante doña Beatriz, do e otorgo al conçeio de Saia Çaharra, a los que agora son e a los que an de seer, que ayan para siempre por so término e por so heredamiento Yembros e Yembros, Sant Yvañes e Sant Yvañes, et estos logares sobredichos los do que los ayan libres et quitos con sos términos e sos montes et con sus aguas et con sus entradas et con sos salidas et con todas sus pertenençias quantas an et deven aver, et que fagan dello et en ello como en su término et su heredamiento. Et mando et defiendo que ninguno non sea osado de yr contra este previlegio deste nuestro donadío nin de quebrantarle nin de menguarle en ninguna cosa, ca aquel que lo fisiesse auríe mi ira et pecharme ya en coto mill maravedis et al conçeio sobredicho todo el daño doblado.

Et porque este mío previlegio sea firme et stable, mandelo seellar con mío seello de plomo.

Fecha la dicha carta en Palençia, por mandado del Rey, .xxix. días andados del mes de mayo, en era de mill et dosientos et noventa e tres años, en el año que don Edoart, fijo primero del rey Henrich de Inglaterra, reçivió cavallería en Burgos del Rey don Alfonso el sobredicho.

Et yo el sobredicho rey don Alfonso, regnante en uno con la Reyna doña Violant, mi muger, et con mis fijas la Infante doña Berenguela et la Infante doña Beatrís, en Castilla, en Toledo, en León, en Galisia, en Sevilla, en Córdova, en Murçia, en Jahén, en Baeça, en Badallós, en el Algarve, otorgo este previllegio et confírmolo.

Don Alfonso [de Molina], la confirma. Don Fadrique, la confirma. Don Enrique, la confirma. Don Manuel, la confirma. Don Ferrando, la confirma. 
Don Felipe, electo de Sevilla, la confirma. Don Sancho, electo de Toledo et chanciller del Rey, la confirma. Don Juan, arzobispo de Santiago, la confirma. Don Aboabdille Abenasar, Rey de Granada, vasallo del Rey, la confirma, et don Mahomat Abenmahomat Abenhuch, Rey de Murçia, vasallo del Rey, la confirma. Don Abenmafot, Rey de Niebla, vasallo del Rey, la confirma. Don Gastón, bisconde de Beart, vasallo del Rey, la confirma. Don Gui, bisconde de Limoges, vasallo del Rey, la confirma.

Don Aparicio, obispo de Burgos, la confirma. Don Pedro, obispo de Palençia, la confirma. Don Remondo, obispo de Segovia, la confirma. Don Pedro, obispo de Sigüença, la confirma. Don Gil, obispo de Osma, la confirma. Don Mathe, obispo de Cuenca, la confirma. Don Benito, obispo de Avila, la confirma. Don Açnar, obispo de Calahorra, la confirma. Don Lope, electo de Córdova, la confirma. Don Adam, obispo de Plasençia, la confirma. Don Pascual, obispo de Jahén, la confirma. Don frey Pedro, obispo de Cartagena, la confirma. Don Pedryváñez, maestre de la Orden de Calatrava, la confirma.

Diego Lopes de Salsedo, merino mayor de Castilla, la confirma. Garçi Suárez, merino mayor del Regno de Murçia, la confirma. Maestre Ferrando, notario mayor del Rey en Castilla, la confirma. Don Nuño Garçia, la confirma. Don Alfonso López, la confirma. Don Rodrigo Gonçales, la confirma. Don Simón Ruís, la confirma. Don Alfonso Telles, la confirma. Don Fernant Roís de Castro, la confirma. Don Pedro Núñez, la confirma. Don Nuño Guillem, la confirma. Don Pedro Gusmán, la confirma. Don Rodrigo Garçía el Niño, la confirma. Don Rodrigo Alvarez, la confirma. Don Ferrant Garçía, la confirma. Don Alfonso Garçía, la confirma. Don Diego Gomes, la confirma. Don Gómez Roýs, la confirma.

Don Nuño, obispo de León, la confirma. Don Pedro, obispo de Oviedo, la confirma. Don Suero Pérez, electo de Çamora, la confirma. Don Pedro, electo de Salamanca, la confirma. Don Pedro, obispo de Astorga, la confirma. Don Leonart, obispo de Çibdad, la confirma. Don Miguel, obispo de Lugo, la confirma. Don Johán, obispo de Orense, la confirma. Don Gil, obispo de Tuy, la confirma. Don Pedro, obispo de Mondoñedo, la confirma. Don Pedro, obispo de Coria, la confirma. Don frey Robert, obispo de Silve, la confirma. Don frey Pedro, obispo de Badallós, la confirma. Don Pelay Peres, maestre de la Orden de Santyago, la confirma.

Gonçalo Morant, merino mayor de León, la confirma. Roy Soares, merino mayor de Galizia, la confirma. Don Suero Peres, electo de Çamora e notario del Rey en León, la confirma. Don Gonçalo Alfón, la confirma. Don Martín Alfón, la confirma. Don Rodrigo Gomes, la confirma. Don Rodrigo Frolas, la confirma. Don Johán Peres, la confirma. Don Ferrant Martines, la confirma. Don Martín Gil, la confirma. Don Andreo, 
pertiguero de Santiago, la confirma. Don Gonçalo Ramires, la confirma. Don Rodrigo Rodrigues, la confirma. Don Alvar Días, la confirma. Don Pelay Peres, la confirma. Roy Lopes de Mendoça, almirant de la mar, la confirma. Sancho Martines de Xódar, adelantado de la Frontera, la confirma. Gonçalo Peres de Toledo, notario del Rey en el Andalusía, la confirma.

Millán Peres de Aellón la escrevió el año terçero que el Rey don Alfonso regnó. 


\title{
DOCUMENTO 4
}

\author{
1255, agosto 13. Valiadolid
}

Alfonso $X$ concede diversos privilegios a los de Cinco Villas en torno al pago del homicidio.

AhPLa Rioja, A.M. Mansilla, 105/16. Original, pergamino.

Cit. Fidel Fita, op. cit., p. 369.

Connosçuda cosa se a todos los omes que esta carta vieren cuémo yo don Alfonso, por la gracia de Dios, Rey de Castiella, de Toledo, de León, de Galizia, de Sevilla, de Córdova, de Murcia et de Jahén.

Por fazer bien e mercet a los de Cinco Villas et a los de Monte Negro et a Biniegra de Suso et a Biniegra de Yuso et a Ventrosa et Brieva et a Mansiella et a Villa Velayo et a Canales et a Monte Ruvio.

Suéltoles todo omezilio achacado et yerra et muebda de omne muerto et aquel que tovieren qu'el mató, que se tornen a él si fuere vezino o fijo de vezino, et si manifiesto fuere de la muerte qu'el dixieren, que peche el omezilio segunt so fuero, et si lo negare que se salve que no'l mató con onze vezinos pecheros et él que sea el dozeno que no'l mató ni'l dio ferida de que muriesse, et que iuren estos dodze sin yerra ninguna et que digan que iuran verdat a Dios et a Sancta María et a todos los Sanctos et a todas las Sanctas que no'l mató ni'l dio ferida de que muriesse. Et, si mintieren, qu'el co[n]funda Dios en este mundo el cuerpo et en el otro el alma, et que responda tres vezes "amén» sin yerra ninguna.

Et si la muerte fue demandada a todo conçejo d[o] lo ellos connosçieren la muerte, pechen el omezilio segund so fuero, et si lo negaren, den dodze vezinos pecheros que iuren sin yerra ninguna, segund sobredicho es.

Et por esta merced que les yo fago an de tener un capellán pora siempre jamás que cante missas por el alma del muy noble rey don Ferrando, mío padre, et por mí et por todos los reyes de mío linage.

Et mando et defiendo que ninguno non sea osado de yr contra este mío carta [sic] nin de quebrantarla nin de menguarla en ninguna cosa, ca qual quiere que lo fiziesse aurie mi yra et pecharmie en coto mill mr. et a ellos todos [el da]ño doblado.

Et porque [esta carta sea firme et] estable, mandela sellar con mi seello de plomo.

Fecha la carta en Valladolit, por mandado del Rey, .xiii. días andados del mes de agosto, en era de mill et dozientos et noventa et tres años.

Millán Pérez de Aellón la escrivió el año quarto que el rey don Alfonso regnó. 


\section{DOCUMENTO 5}

\section{3, septiembre 20. Burgos}

Sancho IV confirma a los de Cinco Villas y Canales los privilegios concedidos por Alfonso VIII, ya confirmados por Fernando III y Alfonso X.

AHPLa Rioja, A.M. Mansilla, 109/14, fol. 122v-124v. Traslado en proceso seguido en 1739.

Cit. Fidel Fita, op. cit., pp. 369-370.

Don Sancho, por la gracia de Dios, rey de Castilla, de Toledo, de León, de Galizia, de Sevilla, de Córdova, de Murcia, de Jaén, del Algarbe, señor de Molina. A bos Juan Rodríguez de Raias, nuestro merino maior en Castilla, e otros que tubieren la tierra. Sabed como a aquel queremos vien y en quien fiamos. Sepades que los conzexos de Montenegro de Brieba, de Bentrosa, de Binegra de yuso e de Mansilla e de Villa Belaio e de Canales e de Monterrubio nos enviaron mostrar nuestra carta plomada, en que viéramos carta de mío padre el rey don Alfonso, que Dios perdone, en que les confirmara una carta de mis padre e abuelo el rey don Alfonso, la qual les tiene confirmada mío abuelo el rey don Fernando, en que les quitaba de todo pecho e yantares e omiguillos [sic] e de fonsado e de fonsadera e otras cosas que pechan a nos los nuestros vasallos e pecheros entre la fiesta de San Miguel e de San Martín, e dixieron nos que aviendo ellos en uso en el tiempo sobredicho de no entrar en sus lugares e villas merino nuestro, de los reies onde nos venimos, e que Domingo Romero, merino que fue de don Sancho Martínez, entrara e que lo querellaron a don Sancho Martínez, el sobredicho, e él por ende que les dio su carta e que nos mostraron, en que él defendió que no y entrasen, e porque nos dixieron temer que vos e algunos de los nuestros merinos quisiéredes y entrar, en nos pidieron merced que lo non aconsintiésemos, porque mandamos a vos e a todos los otros merinos que esta nuestra carta viéreden que non entrades a merinear en ningunos de los lugares sobredichos, lo uue non consentimos, e a nos tenemos por vien e queremos fagades según que obieren falto e qui de nos e de los reies onde nos venimos a los que aiades fecho servizios con vituallas, armas e dinero para contra la moresma e reies enemigos contra nos, por ende que les fazemos e damos nuestra carta plomada e que non pechen ne fagan a sus moradore[s] que son o fueren ende pechar ne les fagan trebuto e para pagar lo que por nos e por nuestros venideros fuese demandado aian de poder e puedan mercar e bender de los suios términos lo que bastase, mediante que los dichos logares e villas están en sierras montañosas e 
mui altas de ella, paguen a nos e a los que de nos vengan lo que de nos fuere menester obiesen e queremos que non por ello mengüe la su nobleza e que les sea guardada a lo porvenir, e que esta nuestra carta le sea siempre firme a baledera e presentes sus buenas fazañas, dezimos que si bos e otro merino qualesquier quisiéredes mostrar que debedes entrar a merinear, benimoslo a dezir e nos fazemos aplasar sobre ello e librarlos emos como falleremos por derecho, sacarla, leída dárxela sellada, entregarla. En Burgos, veinte dias de septiember, hera de mill treszientos y treinta y un año. Agustín Pérez la mandé fazer por mandado del rey. Yo Gonzalo Rodríguez la fize escribir e puse mi signo. Álanse en el previlexio dos firmas que no se perziven por su antigüedad y estar turbadas. 


\section{DOCUMENTO 6}

1328, noviembre 20. Madrid

Alfonso XI confirma a los de Canales y su tierra los términos antiguos.

AHPLa Rioja, A.M. Mansilla, 109/14, fol. 138r-141r. Traslado en proceso seguido en 1739.

Don Alfonso, por la grazia de dios, Rey de Castilla, de Toledo, de León, de Galizia, de Sebilla, de Córdova, de Jaén, del Algarbe e señor de Molina. A bos, Fernán Pérez de Portocarrero, nuestro merino maior en Castilla, y los merinos e merino que en adelante hubieren por nos e por los agora e de aquí adelante en las merindades de Castilla o en qualquier de ellas, o a bos Diego López de Ascuriaga, merino de la merindad de Cinco Villas e Balle de Canales, $o$ a otro qualquier que fuere merino en la dicha merindad agora $e$ de aqui adelante, o a qualquier o qualesquier de vos a quien esta nuestra carta fuere mostrada o el traslado de ella, signado de escrivano público sacado con autoridad de alcalde e de juez. Salud y grazia.

Sepades que los de Canales con sus villas nos enviaron dezir cómo an previlexio de los Reies, enperadores que fueron en Castilla, en que se contiene que les fazieron merced que hubiesen y usasen con sus ganados paziendo las yerbas e bebiendo las aguas de día y de noche en estos términos deslindados que se siguen: desde Cogalla al Follagri Cotero al Cuerbo e a Sierra Corta e a la Cogolla de Aranda e por Ronuo e Mediano a Sinestra Redondo e Río de Aranda e pos fasta la Bega del Toro e Canpo Luengo suso Castexón de Becareda e por el sendero al Campo de Sueso de Lombo de Zerezo y al puerto fasta los Foios de Monterrubio a San Cristóbal Calero con Testero a la Peña del Güitre e a la Peña de Caldo e a Santa Conba con la Lasta aiuso a Somo Granón a la Caveza Maior de Gramón y a Matacuero y al Río de Neila e a Campo Alegre a o somo Ferrara e al Collado de Piedra Fita e a la Puerta del Pozo de Guedra e a Tormes Altuos e al Collado Grande e al Collado Gutial e al Cavezo de Taolades e al Collado Cavallas e a Peña Ruvia e por Lomillo de las Codrellas que dende al Canpo e fuera al Río de Neila e Río aiuro a Covilla, Villacete como de Caragozano aluso a la Caveza de la Andrina e dende somo fasta la Cuesta del Foio Vellido a el Collado de Guiterto e a la Caveza de Regazal e dende a Colla.

E agora dizen que por razón del dicho previlexio que tienen como dichos que ellos entraron en los dichos términos e que usaron de ellos después acá fasta aquí sin enbargo ninguno y que usan oi día, enviáronos pedir por merced que pues ellos tienen los dichos términos usan en ellos sin enbargo ninguno, como dicho es, e les fue así guardado en tiempo de los dichos Reies y enperadores y en el nuestro fasta aquí, se lo confirmásemos e se lo 
mandásemos así guardar, según que les fue guardado en el dicho tiempo y en el nuestro fasta aquí, como dicho es.

E nos tubimoslo por vien, porque vos mandamos, vista nuestra carta o el traslado de ella signado, como dicho es, que si los de Canales e sus villas entraron e tienen los dichos términos e usan en ellos sin embargo ninguno, como dicho es, que beades dicho previlexio que tienen en esta razón e que lo guardéis e cumplades e fagades guardar e cumplir en todo, vien e cumplidamente, según que en él se contiene e según que le fue guardado en tiempo de los dichos Reies, enperadores y en el nuestro fasta aquí, e que les non baiades ni pasades ni consintades a otros a otros algunos que les baian ni pasen contra él, según derecho, ca nos tenemos por vien e mandamos que les bala y sea guardado según que les balió y fue guardado en tiempo de los dichos Reies y enperadores y en el nuestro fasta aquí, según dicho es. $E$ los unos y los otros no fagades en[de al], so pena de la nuestra merced y de zien mrs. de la moneda nueba a cada uno; e de cómo bos esta nuestra carta bos fuere mostrada e la culpliredes, mandamos a qualquiera escrivano público que para ello fuere llamado que de'nde a el que bos la mostrare testimonio signado con su signo porque nos sepamos el cómo cumpledes nuestro mandado; e no fagades ende al so la dicha pena e del ofizio de la dicha escrivanía, e desto les mandamos dar esta nuestra carta sellada con nuestro sello de plomo. Dada en Madrid, a veinte días de noviembre, hera de mill e trezientos e sesenta e seis años. Yo Juan Gutiérrez la fize escribir por mandado del Rey. Jil Fernández. Juan Garzía. Vista, Alfonso Garzía. Gómez Fernández. Gonzalo Sánchez.

Confirmado en las Cortes de Toro, 5-IX-1371.

Idem en Valladolid, 26-V-1405.

Idem en 14-[mes en blanco]-1420. 


\section{DOCUMENTO 7}

\section{4, agosto 11. Burgos}

Alfonso XI promete no enajenar de la Corona real los lugares de las Cinco Villas.

AHPLa Rioja, A.M. Mansilla, 105/17. Original, pergamino (falta el sello, hay restos de cintas roja, blanca y amarilla).

Cit. Fidel Fita, op. cit., p. 372.

Sepan quantos esta carta vieren cómo nos don Alfonso, por la gracia de Dios, rey de Castiella, de Toledo, de León, de Galisia, de Sevilla, de Córdova, de Murçia, de Jahén, del Algarve, e señor de Vizcaya e de Molina.

Porque los concejos de las villas e logares de Cinco Villas con Val de Canales nos reçebieron e tomaron por su señor e nos pidieron merçed que fuessen siempre en la Corona de los nuestros Regnos e que los non diéssemos a reyna nin a Infante nin al rico omne nin a rica dueña nin a otro ninguno, porque otro oviesse el señorío della sinon nos e el que regnasse depués de nos en Castiella e en León.

Nos por esto e por voluntad que devemos de faser bien e merçed a los conçejos de las villas e logares de Cinco Villas e Val de Canales, et porque es nuestro serviçio, toviémoslo por bien e otorgámosles que sean siempre en la Corona de los nuestros Regnos e de los que regnaren depués de nos en Castiella e en León para siempre yamás.

Et desto le mandamos dar esta carta seellada con nuestro seello de plomo.

Dada en Burgos, onse días de agosto, era de mill e tresientos e setenta e dos años.

Yo Rodrigo Rodrigues la fis escrevir por mandado del Rey. Ruy Martines. Alfonso Yañes. Diego Peres. 


\section{DOCUMENTO 8}

1366, septiembre 25. Sajazarra - 1399, febrero 12. Sajazarra.

El concejo de Sajazarra aprueba un conjunto de 38 ordenanzas en materia de Derecho penal y de policía rural, redactadas en cinco ocasiones consecutivas.

AHPLa Rioja, A.M. Sajazarra, 24. Original, pergamino; todos los textos son originales y anotados uno tras otro.

Ed. Moya Valgañón, op. cit., doc. 3, pp. 125-127.

[En] veinte e çinco días del mes de setiembre, era de mill e quatroçientos quatro, ante los puentes de Santa María de Saja Çaharra, estando yuntado el conçejo de Saja Çaharra a campana tañida, según que lo an de uso e costumbre, con Johán Lopes, alcalde, e con Ferrán Peres e con Martín, jurados del dicho conçejo, este día se obligaron a se mantener estas posturas que aquí serán escriptas, para los que aquí son e serán de aquí adelante, por escusar muchos daños e contiendas, e por voluntad de todos los vesinos e vesinas del dicho logar pusieron estas posturas que se siguen, e que valan para agora e para todo tiempo:

[1] Lo primero, ponemos que todo aquel que peleare con otro vesino e sacare guchiella e non firiere, que peche treinta e ocho mrs.; e sy firiere que peche çient mrs. e sobre esto que yaga nueve días en el çepo.

[2] E todo omne o muger que peleare uno con otro e llamare uno al otro "fodydo", que peche veynte mrs.

[3] Otrosý, todo omne que peleare con otro e el firiere uno a otro de piedra o de palo, que peche quatro mrs. por cada una.

[4] Otrosý, sy alguno peleare un omne con otro e llamare uno a otro "traydor" o "fidetraydor", que peche por cada una ves que lo llamare ochenta mrs.

[5] E si llamare "fidefudyncul», que peche veynte mrs. por cada ves.

[6] E otrosý, qui llamare "fideputa susir» e «fideputa probada" o «fideputa carcabera", que peche por qualquier destas palabras veynte mrs.

[7] E otrosý, qualquier que llamare uno a otro "malato" o «fidemalato", que peche por qualquier deste çient mrs.

[8] E sy llamare uno a otro "astroso" o "fideastroso" o "mesiello" o "fidemesiello", o "cornudo" o "fidecornudo", por qualquier desto que peche treynta mrs.

[9] E sy non obiere de qué los pechar, que quantos días yoguiere en el çepo que quite por cada día çinco dineros de los nuebe días adelante. 
[10] $E$ todo omne o muger que desmintiere a otro, que peche veynte mrs.

[11] E otrosý, qualquier que llamare palabras que sean semejable destas o qualquier destas, que peche assý como se contiene en las posturas escriptas.

[12] E otrosý, qualquier vesino que non viniere a conçejo oyendo la campana, que peche quatro dineros.

[13] E sy qualquier que saliere en bando pele[a]ndo algunos, que peche çient mrs. e que yaga nuebe días en el çepo.

[14] E otrosý, sy acaeçiere refierta un vesino con otro por caminos o goteras o sulqueros o mujonas o regeras o por otra manera, qualquier que sea ende los que esto acaeçiere e ellos non se queriendo abenir, e los beedores del conçejo obieren yr a berlo, peche el que tubiere la culpa dos mrs., fuera de las costeras, e de las costeras adentro, que peche dose dineros.

[15] E todo omne o muger que cortare en viña o en uerto ajeno e fisiere daño, peche quatro mrs., uno al costigero e tres all conçejo.

[16] E sy el costigero trayere ubas o fruta o ortalysa a su casa, que peche ocho mrs.

[17] E otrosý, [sy] el costigero tobiere otros omnes en la cabaña o en las biñas, que peche quatro $\mathrm{mrs}$.

[18] E otrosý, qualquier que obiere uerto et non limpiare la segera en su derecho, del día que gelo fisieren saber fasta ocho días, que peche quatro mrs.

[19] E sy regare e non tornare el agua a la madre, en[de] que peche un $\mathrm{mr}$., los çinco dineros para aquel que lo acusare e los otros çinco para el conçejo.

[20] Otrosý, qualquier que jugare dados vesino con vesino, que peche dies mrs. por cada ves e que yaga nuebe días en el çepo.

[21] E otrosý, sy entraren ansares en las viñas o en las mieses o en los uertos o en las eras, que peche por çinco ansares tres dineros.

[22] E sy entrare bestia o bué o baca en m[i]eses, dos dineros.

[23] E en las viñas de mient obiere fruto, çinco dineros, e en otro tiempo dos dineros.

[24] E otrosý, sy entrare en viña o en miese o en uerto el puerco, que peche çinco dineros.

[25] E qualquier que la mañana de Sant Johán cortare ramas en álvor ajeno, peche quatro mrs. al conçejo e al dueño el daño doblado.

[26] E otrosý, sy alguno vesino cortare alguna cosa de las coseras a bender para trébede en la villa de los que se vinieren a vender a la villa, syn faser pan, que peche çinquenta mrs. 
[27] E otrosý, sy alguno llamare un vesino a otro "venediso", que peche çient mrs.

[28] E otrosý, sy alguno vesino fisiere alguna cosa que non deba faser e fisiere el conçejo justiçia sobre ello, que el que gelo diere que en reganyo, que peche çinquenta mrs.

[29] Otrosý, ponemos que qualquier vesino que jugare a seca nin a faser, que peche por cada ves dies mrs. para el conçejo e que yaga nuebe días en el çepo.

Testigos que fueron presentes Johán Miguel Capilla e Johán Martines de Rasa e Johán fijo del monje, e yo Gonçalo Peres, escrivano público que de Saja [so], que presente fuy a todo lo sobredicho con los dichos testigos, con ruego e mandado del dicho conçejo, fis aquí esta carta de compusiçión e fis en ella este mío sygno en testimonio de verdat. Gonçalo Peres.

[30] Otrosý, mandaron el dicho conçejo e omnes buenos e otorgaron que qualquier vesino o vesina del dicho logar que dixiese o en denuesto le ablare por rasón de la entrada que los ingleses fisieron en el dicho lugar de Saja por qualquier manera, que pechase por pena e en postura por quantas veses lo dixiere por cada ves dosientos mrs. a el conçejo, e que salga qualquier que lo dixiere, varón o muger, vesino del dicho logar por malo e [borrado]mada del dicho logar de Saja e ningún que por él pasare que en esto cayere, que sea la pena mesma qu'el otro que lo fiso desir otro [borrado].

Testigos, los sobredichos. E esto escripto bala como lo de suso del sino, que yo Gonçalo Peres, escrivano sobredicho, la fis por mandado del dicho conçejo, e por ende pusy aquí mío nombre. Gonçalo Peres.

[31] Otrosý, ponemos que sy alguno vesino fue a querellar del alcalde syn lo querellar al conçejo, que peche çient $\mathrm{mrs}$.

[32] Otrosý, mandaron el dicho conçejo que sy por ventura acaesçiere algún lyvor de algún ganado, como de muerte, [ferida], o de muerte [o] de otra [manera], que vean los veedores del conçejo e gelo apreçien, que el conçejo que pa[gu]e la meytad de lo que pagaren los dichos [borrado], que sy esto se perdiere por mengua de ganaderyso, que lo pague hel ganaderyso.

[E porque] es verdat, puse yo Ferrant Martines este dicho mío nombre. Ferrant Martines.

[33] Otrosý, mandamos e tenemos por bien que qualquier alcalde o cogedor que fue en el logar de Saja, que de aquí adelante que peche en los pechos que vinieren de aquí adelante, la mitad de que [roto]lys biniere sueldo por libra, porque sea firme por agora en todo tiempo, mandaron a mi Ferrán Martines escrivano que pusiese aquí mi nombre. 
[34] E mandamos que por ningún pecho nin deuda ninguna que sea que ninguno non sea osado de pedir carta o cartas syno fue por su [solera] de vesino ninguno, so pena de dies mrs. por cada vegada.

En dose días de febrero, año del nasçimiento de Nuestro Salvador Jesuchristo de mill y tresientos y noventa y nueve años, este día en Saja Çaharra, en la eglesia de Sant [Miguel] del dicho logar, estando y yuntado el conçejo del dicho logar a campana tañida, según que lo an de uso y de costumbre, estando yo Pero Martines lorry alcalde del dicho logar, en presençia de mí Juan Días, escrivano público del dicho logar, estando el dicho conçejo e alcalde e omes buenos, ordenaron e mandaron por serviçio de Dios e por [bien] de pas, esto que se sigue:

[35] Que ningún vesino del dicho logar que non trayga cuchillo ni espada en la villa, y quien lo truxiere que pague en pena çien mrs., la meytad desta pena en la çerca de la villa e la otra meytad en el acusador.

[36] Otrosý, qualquier forano que viniere a esta dicha villa, que en la possada que possare que gelo faga saber que dexe el cuchillo, e [sy] gelo non fisiese, que pague en pena el tal vesino dies mrs., la meytad para la çerca e la otra meytad para el acusador.

[37] E sy el forano non quisiere dexar el cuchillo o el espada, fasiendo gelo [saber, que] gelo tomen el cuchillo.

[38] Otrosý, que en tiempo de agosto, mientre el pan estoviere en las eras, que la ay[ilegible] que ánades que acaesçieren en las eras, que paguen por cada logar medio dinero en cada agosto por cada ánade en días. Juan Días. 